\title{
Physical Models and Innovation in Architectural and Civil Engineering
}

\author{
Bill Addis ${ }^{1,2,3}$ (D)
}

Accepted: 1 June 2021 / Published online: 16 June 2021

(c) The Author(s) 2021

\begin{abstract}
The author presents new and rediscovered information about the use of physical models in design processes carried out by architectural and civil engineers. Over the last three centuries these have included mechanical models, form-finding models and measurement models. Measurement models especially were and are particularly important for innovative engineering projects that lie beyond current experience or are without precedent. In these cases, to supplement their own experience and current engineering science, engineers require additional evidence that their innovative designs will function as intended, will be safe, and in which they can have sufficient confidence to allow construction to begin. The author argues that physical models have played and continue to play an essential role in innovation in engineering and that they have made a contribution equal to that of engineering theory in helping to achieve progress in engineering. Examples are taken from the history of structural engineering, especially reinforced-concrete and grid shells and from architectural acoustics.
\end{abstract}

Keywords Physical models · History · Engineering design · Innovation · Shell structures $\cdot$ Building acoustics

\section{Innovation in Architectural and Civil Engineering}

There are several ways in which a construction project can be innovative and, by definition, these involve designing and making something that has not been done before. The examples used in this paper are drawn mainly from structural engineering, but could equally be taken from other branches of architectural

Bill Addis

bill.addis@cantab.net

1 August-Wilhelm Scheer Visiting Professorship, Technical University, Munich, Germany

2 Buro Happold Consulting Engineers, London, UK

344 Fairfax Road, Middlesex, Teddington TW11 9BZ, UK

Birkhäuser 
and civil engineering (Addis 2007). First, and rather rarely, a design may be an entirely new type of structure or structural technique. For example, the tensile structures of Frei Otto made with a polyester membrane, or the cable-net structures he developed at the University of Stuttgart for the German Pavilion at the Montreal Expo in 1967 and for the Munich Olympics in 1972. Another example is the use of prestressing in reinforced concrete that was developed by Eugene Freyssinet in the late 1920s.

More often, innovation takes the form of building something familiar but, in some way, beyond previous experience. It could be a longer span of a certain type of bridge or roof, or one of similar size but very much lighter in weight, or built in a new way that is cheaper or quicker to construct. It might be a familiar type of structure made of a new or unfamiliar material, or it might have to carry much greater loads than previously, as was the case for the first iron railway bridges in the 1830 s and 1840 s.

A third way in which a structure might be innovative is that it may be designed in a new way, perhaps making use of new engineering science or, indeed, using engineering science for the first time.

Finally, an innovative structure might be of a familiar kind, but used in an unfamiliar context or situation with its own unique characteristics, which means it needs to be designed differently. For example, a long-span roof for a building in an earthquake zone, or a building built on ground with a highly fluctuating water table. In fact, a large number of building projects have their own unique characteristics or constraints, which is why it is seldom possible to use and reuse 'standard solutions' in the construction industry.

Occasionally there have been projects which have required innovation in all four of the ways just described. The Britannia bridge in north Wales, designed and built by Robert Stephenson in the 1840s, was such an example. It was a box-girder bridge, made of wrought-iron plates, which had to carry railway locomotives across a span of unprecedented size-140 m-and designed at a time when engineering theory was not able to address the problem of buckling in iron plates loaded in compression. During the design process, more than 40 wroughtiron models at scales of between 1:33 and 1:6 were built and, in some cases, rebuilt after collapse, and re-tested (Addis 2021: 187-203) (Figs. 1, 2).

Generally speaking, then, innovation in engineering takes place when something about a new project takes it into the unknown, where precedent is of

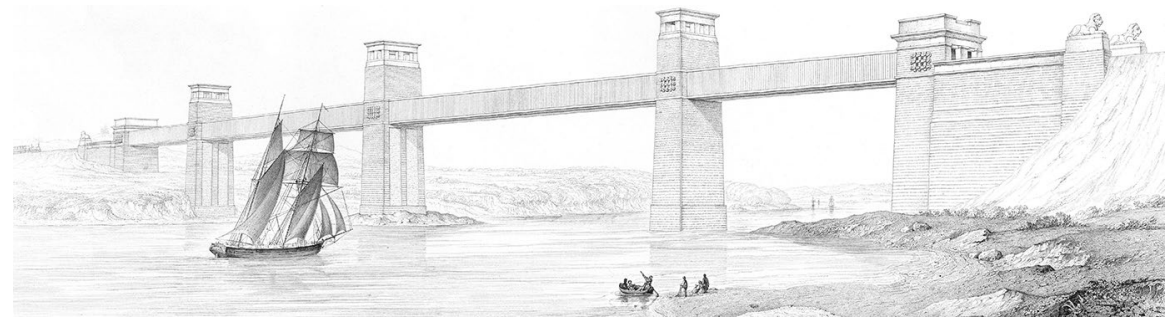

Fig. 1 Britannia bridge across the Menai Strait in North Wales. (Image: Clark 1850, Plate VI) 


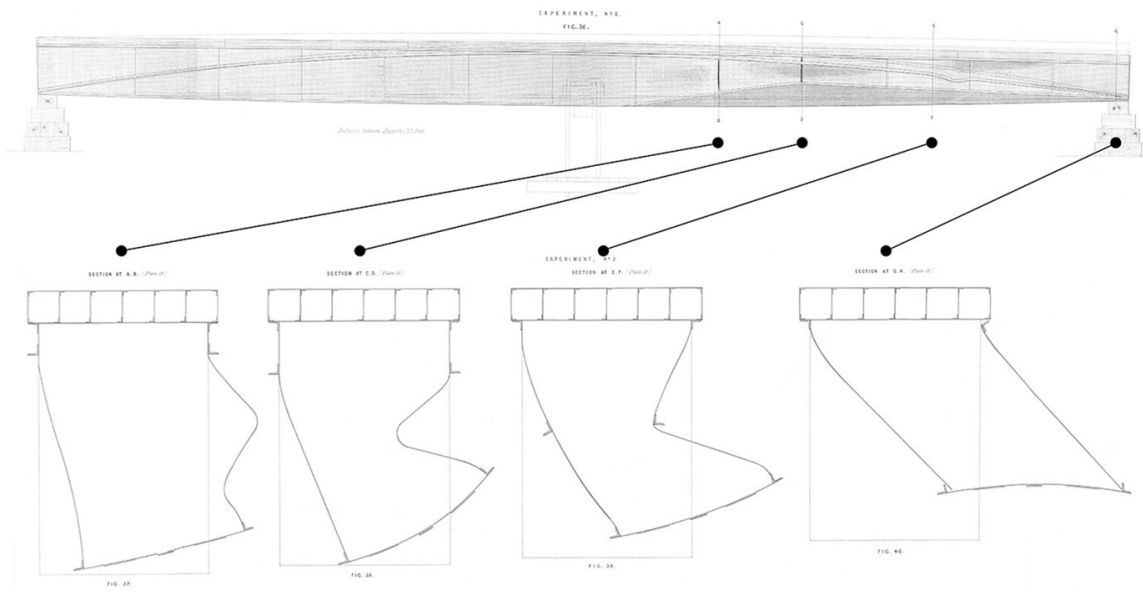

Fig. 2 Above: Failure of a model by sway buckling of the side walls. Below: Deformed shape at four sections on the right-hand half of the girder. (Image: Fairbairn 1849, Plates XVIII and XIX)

limited help. Once the unknown has become familiar, the boundary defining the limits of precedent moves; such is the essence of progress in engineering (Addis 2003).

\section{Design in Engineering}

Engineering design usually involves three key stages. First, a structural solution has to be proposed which responds to the project brief and the various external constraints. Potentially this is the most creative stage of the process. Different structural solutions may be proposed and one chosen after a rigorous comparison of the pros and cons of the alternatives.

The second stage involves the detailed design of individual components leading to a specification of the structure-the materials used, the dimensions and the relative dispositions of the elements, a method of construction.

Thirdly, it is necessary to communicate the design to the entire project team so that it can be built.

A fourth strand of the design process proceeds simultaneously and in parallel with the other three stages. The designer must also provide adequate evidence that the design that has been proposed will work, will be safe and can be built. Initially, it is essential that the designers themselves are convinced of its adequacy; it is then important to convince everyone else involved in the project—especially the client, the builder and the regulatory authorities (Addis 1990, 1999).

This latter strand of the design process amounts to generating sufficient confidence that the design is viable, safe and can be built. Physical models have been, and are, used in projects to contribute to generating sufficient confidence in a proposed design. Before looking at how models are used in innovative projects, it will be helpful to 
consider the various ways in which an engineer can build up the level of confidence in a design that is needed before construction can be allowed to begin.

\section{How Confidence in a Design is Generated?}

The most fundamental source of confidence is to be found in precedent. If a new project is the same as many that have been successfully completed before, then the level of confidence in the new design will be very high. For an individual engineer or builder this is largely what is embodied in the idea of 'experience' and what it is to learn and master a technical skill.

The challenge for the engineer is what to do when a proposed design is beyond their experience. However, it is also a matter of judgement as to precisely what is meant by 'beyond'. If a roof is $5 \%$ wider than previously built, that will probably be safe. But how about $10 \%$ or $20 \%$ or $50 \%$ ? At what point does an engineer's confidence fall below they consider sufficient? And if the level of confidence is felt to be insufficient, what can the engineer do about it? Furthermore, if the engineer manages to achieve what they consider to be sufficient confidence, how can they convince other members of the project team and the regulatory authorities?

Over the centuries, engineers have used many ways of raising their own level of confidence in a design, and to persuade others (Addis 1990). These include:

- Using precedent (previous examples are, effectively, successful full-scale tests);

- Using simple calculations based on engineering science, together with precedent, for example, increasing the span of a roof by a small amount;

- Using design procedures that are well-established (not infallible if a new structure is different in an unforeseen way);

- Basing a design on an individual engineer's experience (but it may be difficult to persuade others);

- Using calculations based on established engineering science;

- Building and testing a full-size prototype (but this is unrealistic for most construction projects);

- Making experiments with a reduced-scale model.

This review of innovation and the design process in architectural and civil engineering provides a context in which the use of physical models by engineers can be understood. If a project is beyond normal experience and beyond the scope of contemporary reliable science, then a truly innovative solution is required, for which building and testing a reduced-scale physical model is likely to be the only way of generating sufficient confidence in a new design to allow construction to begin.

\section{Physical Models in Engineering}

The physical models that design engineers have used fall into three broad categories, although there is often some overlap between them (Addis 2005, 2013): 
- Models that test whether something works, in a mechanical way;

- Models built at small scale that determine the form of a full-size structure;

- Models that aim to replicate, in miniature, how a large structure will behave when subject to the loads it will need to carry at full scale.

\section{Mechanical Models}

Engineers have used models to test whether something works before building it at full scale for a very long time. Writing in about 15 BC, in Book X, Chap. XVI, Vitruvius mentions testing models of various items of military engineering. Sadly, most models that served as a 'proof of principle' for an innovative design and demonstrated its effectiveness to potential clients have been lost. However, a particularly rich collection of mechanical models has survived in the 'model chamber' in Augsburg in Southern Germany. These were made mainly by Elias Holl (1573-1646) and Caspar Walter (1701-1769), who were the principal civil and mechanical engineers of Augsburg's renowned water distribution system. Among the collection of 126 models are pumps, water towers, water wheels, sluice gates, bridges, roof trusses and various pieces of construction machinery. Other similar collections from the time include cranes, boring machines, pile drivers and other construction equipment. Such models also served to communicate details of their construction to the builders of the full-size artefacts (Bühler 2021).

In more recent times, the great Japanese engineer Mamoru Kawaguchi (1932-2019) used mechanical models to test the innovative erection procedures he devised for several huge sports stadia and wide-span buildings, such as those using his Pantadome system (Kawaguchi and Abe 1992; Kawaguchi 1998; Chilton 2000: 139-151) (Fig. 3).

\section{Form-Finding Models}

In the 1670s, Robert Hooke formulated his law of the catenary, which stated that a masonry arch would be stable if its form was the same, but inverted, as a (model) hanging chain weighted with stones similar in proportion to those in the arch. This discovery led directly to a new way of demonstrating the stability and safety of a masonry arch, vault or dome. Hooke used this method to verify that the shape of the innovative dome proposed by Christopher Wren for St Paul's Cathedral in London
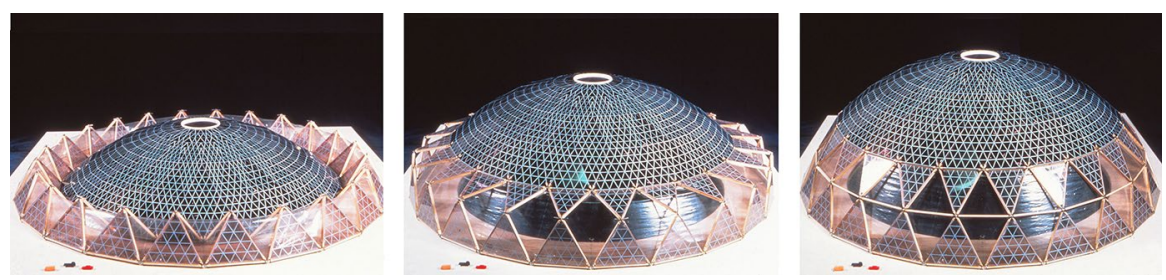

Fig. 3 Small-scale generic model (1:100) to study the mechanical mechanism and erection procedure for the Pantadome. (Image: Mamoru Kawaguchi) 

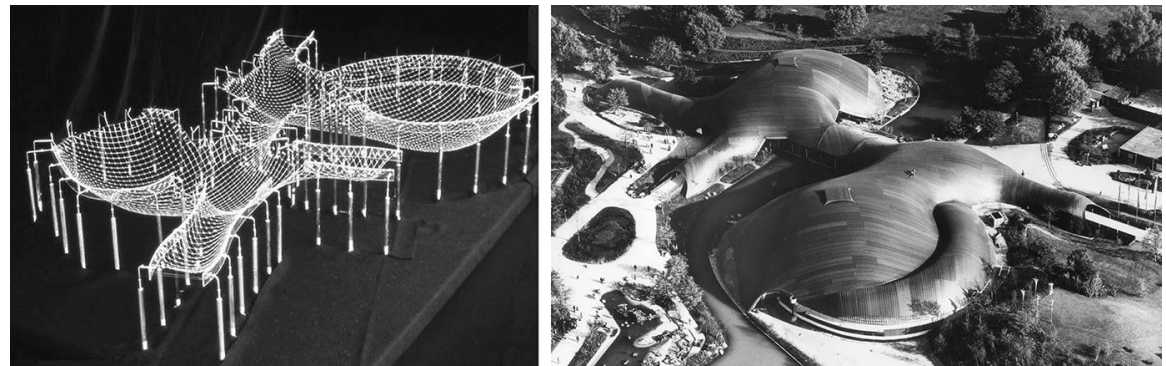

Fig. 4 Multihalle at the Mannheim Bundesgartenschau. Left Hanging chain model (Image: Institute for Lightweight Structures, Stuttgart). Right the finished timber gridshell. (Image: Arup)
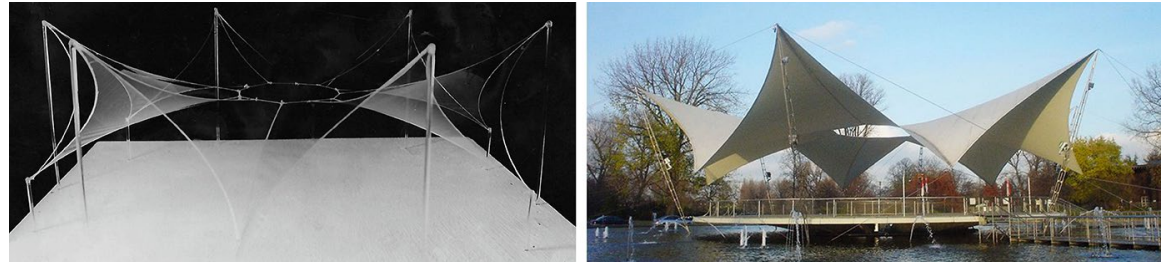

Fig. 5 Sternwellenzelt at the Tanzbrunnen in Cologne, 1957. Left Soap film model (Image: Courtesy of Institute of Lightweight Structures, Stuttgart). Right The finished canopy (Image: Berthold Burkhardt)

would be stable. This was done at a time before the modern science of statics was available to verify this stability and safety.

Making use of Hooke's law of the inverted catenary, many engineers and architects have determined the form of innovative compression structures by creating hanging models and inverting them (Addis 2014; Graefe 2021). Some well-known examples are the masonry vaults of Antoni Gaudí (1890s), the concrete shell roofs by Heinz Isler (1960s-1970s) and the timber gridshell designed by Frei Otto with Ove Arup for the Multihalle at the Mannheim Bundesgartenschau in 1973 (Happold and Liddell 1975) (Fig. 4).

A key feature of all these structures is that the modelling process not only creates a form-anyone can create a random form-but creates an ideal form that functions perfectly as a structure in its own right subject to gravity loads.

In the 1960s, the architect Frei Otto worked with various engineers to create a number of innovative tensile structures using polyester membranes. It was not possible to calculate the precise geometry of these structures using statics, and their form had to be determined using experiments with small-scale models made using fabrics or soap films. One example was the Sternwellenzelt at the Tanzbrunnen in Cologne (Bach et al. 1987) (Fig. 5).

Although the form-finding process appears very simple, it is important to note that it was/is never used as the only means by which a structural form was determined. Engineers also made calculations using the theoretical models of statics and elasticity. Often, geometrical data gathered using a physical model were/are used to inform the process of theoretical modelling, and vice versa. Furthermore, 
form-finding models generally represent only two types of loading: gravity and internal prestressing forces. If other loads are imposed, for example wind, then the equilibrium form changes in response to the new loads. In practice, the action of wind loads is calculated using theoretical modelling, although the magnitude and direction of the wind loads may be determined using wind-tunnel modelling.

\section{Measurement Models}

The most productive models used by engineers when designing innovative structures during the last 200 years or so have been 'measurement models' (a translation of Messmodelle in German). These have been used since the mid-eighteenth century, following a track parallel to the evolution of experimental science in general, and the development of structural theory, since the Age of Enlightenment.

A measurement model is built at reduced scale to represent a full-size structure in miniature with the aim of replicating the behaviour of the full-size structure. In order to be reliable, there must be sufficient similitude between the model and the full-scale structure. Scaled loads are applied and deflections of the model and surface strains are measured with dial gauges and strain gauges respectively (Fig. 6). These data are used to determine the forces and stresses inside the model structure, which can then be scaled up to predict forces, stresses and deflections in the full-size structure.

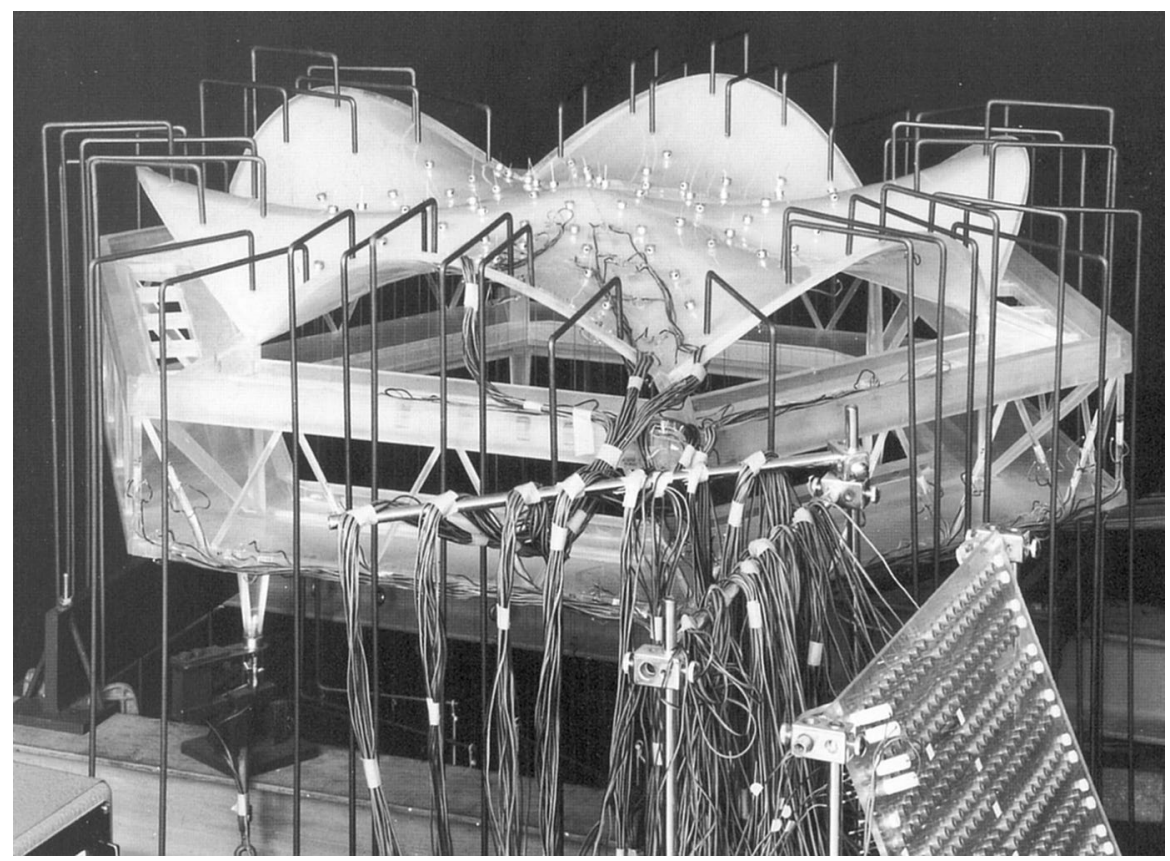

Fig. 6 1:20 Scale model in acrylic resin of the roof for the University Library, Basel, 1964. (Image: Heinz Hossdorf) 
The results derived from experiments using measurement models were/are never used on their own. They were always used alongside the best available theoretical calculations that could be made for the behaviour of the structure. This process could serve to increase confidence in an innovative design, both by using the data from the physical model to corroborate the results from the theoretical model, and by using the theoretical model to validate the whole physical modeltesting process itself. In many cases, measurements were also made of the fullsize structure when subject to real-world loading. This could then give a final validation of the physical model tests and the theoretical model studies which would further increase the confidence with which both could be used in a future project.

Engineers engaged in nearly every branch of architectural and civil engineering have used measurement models for innovative projects, and models have played an essential role in achieving progress in engineering design and construction in these fields. Indeed, they have played a part no less important than that of engineering science and theory in achieving progress in architectural and civil engineering. Table 1 indicates approximately when measurement modelling began to be used for innovative engineering design in various fields of engineering (Addis 2021).

Some case studies of innovative projects are presented in "Some Case Studies", but first there needs to be some discussion of how the results of model tests can be scaled up to full size.

Table 1 Introduction of measurement modelling for innovative engineering design in various engineering disciplines

\begin{tabular}{ll}
\hline Engineering discipline & Introduction of measurement modelling \\
\hline Design of masonry vaults and arch bridges & Mid-eighteenth century \\
Design of suspension bridges & $1820 \mathrm{~s}$, and especially 1930s \\
Hydraulic and free surface water engineering & $1870 \mathrm{~s}$ \\
Wind engineering/wind tunnels & $1890 \mathrm{~s}$, and especially 1980s \\
Seismic engineering (shake-tables) & $1890 \mathrm{~s}$ \\
Design of masonry dams & $1890 \mathrm{~s}$ \\
Acoustic engineering & $1910 \mathrm{~s}$ \\
Design of reinforced-concrete arch bridges & $1920 \mathrm{~s}$ \\
Design of reinforced-concrete dams & $1920 \mathrm{~s}$ \\
Design of reinforced-concrete shells & $1920 \mathrm{~s}$ \\
Centrifuge modelling in geotechnical engineering & $1930 \mathrm{~s}$ \\
Design of tensile structures (membranes, cable nets) & $1950 \mathrm{~s}$ \\
Fire safety engineering & $1960 \mathrm{~s}$ \\
Air movement in buildings for natural ventilation & $1990 \mathrm{~s}$ \\
\hline
\end{tabular}




\section{Scaling Up the Results of Model Tests}

It is probably intuitive to think that results obtained using a model that is $1 / 10$ full scale can be scaled up simply by multiplying the results by the geometric scaling factor of ten. Unfortunately this is not the case, as a simple example can illustrate. If a cube is scaled up by a factor of ten, then the area of one of its faces will increase by 100 , and its volume or mass by 1000 . This observation was first published by Galileo Galilei in 1638 and is called the 'square-cube' law; he used it to prove that there was a limit to the size of animals, due to the strength of bone material and the relationship between body mass and surface area (Galilei 1638: 130-132).

Nevertheless, in the field of engineering structures, there are some phenomena that are independent of scale. It must be considered fortuitous that the simplest form of construction-piling one stone on top of another-is a scale-independent phenomenon. The stability of a wall, or a column in a Greek temple, against the lateral loads from wind depends only on the geometry of the structure: if all dimensions are increased, say, by ten, the safety of the structure against overturning remains the same.

The form of a hanging chain - a catenary-is also independent of scale. This is significant for the stability of arches since, following Hooke's law of the arch, a masonry arch (acting in pure compression) is stable if its form is that of a corresponding catenary (acting in pure tension), but inverted. Hence the stability of masonry arches - and vaults, domes and flying buttresses-is also independent of scale. Although Hooke formulated his law in the 1670s, its practical implications for masonry construction were known since Roman times and spectacularly demonstrated in Gothic cathedrals (Huerta 2021). Thus, the stability under gravity loading of a model cathedral three metres high would give confidence to building the real cathedral 50 or $60 \mathrm{~m}$ high. It is due to the fact that the stability of masonry structures is independent of scale and, hence, that models could be easily and reliably used to explore the viability of innovative structures, that masonry construction developed so dramatically from ancient Greek times, through the wonders of Roman engineering and Gothic cathedrals, to the great vaults and domes of the Renaissance.

A second class of engineering issues that are independent of scale (within sensible limits) are the geometrical arrangements and movements of mechanical models discussed above (see Fig. 3). A reduced-scale wooden model of a water pump could be scaled up, say, five times and the mechanism would still work. Likewise, the complex geometry of interlocking pieces in the three-dimensional connections used in large timber roof trusses and timber bridges in the eighteenth century could be solved using small models of such connections. Physical models of complex connections in timber bridges and roof trusses were widely used at least since the 1600 s, both to work out the complex three-dimensional geometry and also to serve to teach apprentices their art and, in lieu of drawings, to communicate the complex geometry to the carpenters who would have to build an innovative structure (Fig. 7). 


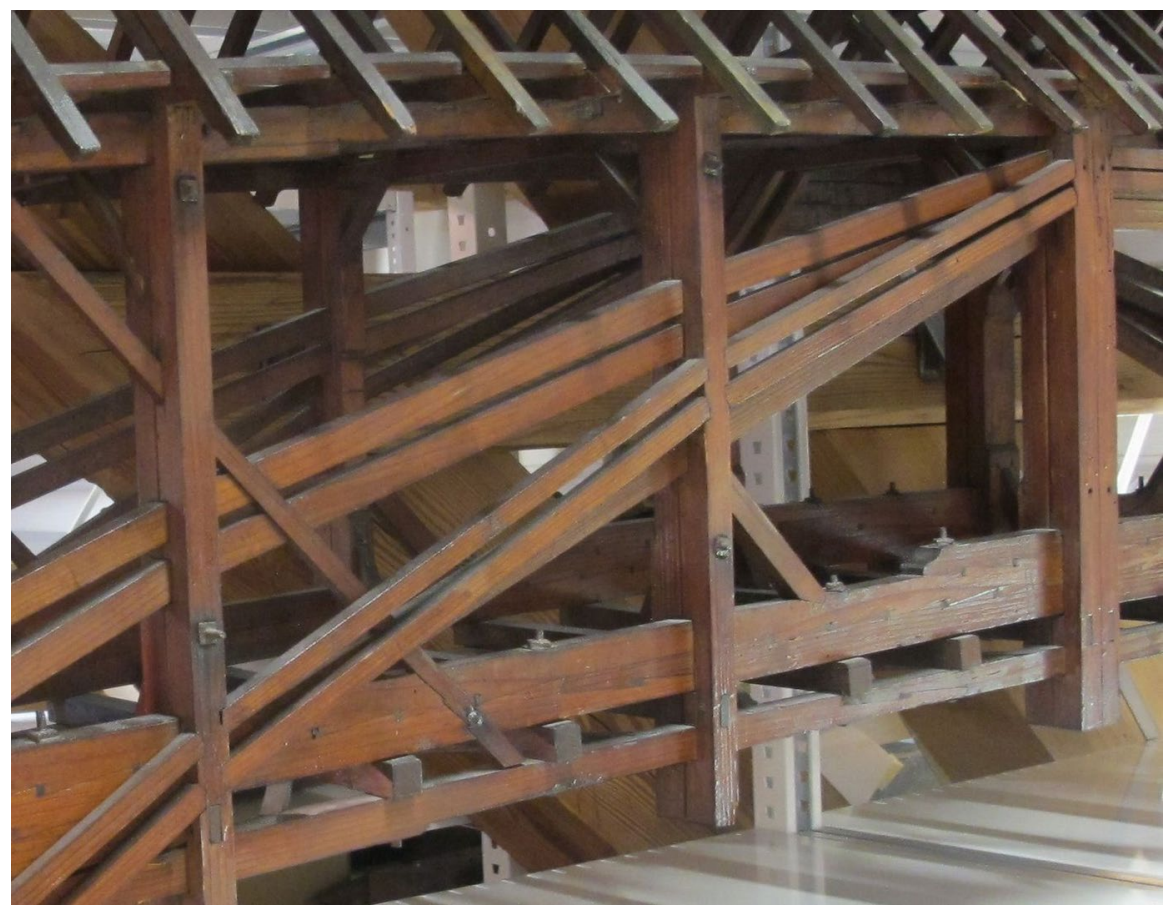

Fig. 7 Original model of the 'Trogen bridge' made by the Grubenmann brothers (around 1745-1755), Grubenmannmuseum, Teufen, Switzerland. (Image: Dirk Bühler)

It has long been known that the observations of some models cannot be reliably scaled up in a simple, linear way-indeed Vitruvius mentions this in his Book X, Chap. XVI with regard to some military siege engines. Taking a simple example from structural engineering, if a reduced-scale beam is loaded in bending, then its stiffness and strength cannot be scaled up linearly to full-size. Furthermore, if the model is made of a different material, the scaling factor will again be modified. The scaling factor depends on what we now know as the theory of bending. Once the theory of bending was known (say, from the mid-eighteenth century) it was, in principle, possible to scale up the results of a small-scale test to full size. The first author to give a rigorous discussion of scaling was Leonard Euler in his paper entitled (in English translation from Latin) 'A simple rule to determine the strength of a bridge or similar structure, on the basis of the known strength of a model' (Euler 1776).

Euler's paper did not become widely known and it was 70 years before the question of scaling was again addressed in detail, by the engineers of the Britannia railway bridge in North Wales in the mid-1840s (see Figs. 1, 2). During the design of the 140-m-span wrought-iron box girder, they tested over forty reduced-scale models and used simple bending theory to determine the correct scaling factors. However, the designers of the Britannia bridge were faced with an impasse concerning the buckling of thin wrought-iron plates subject to compression. There was no adequate 
elastic theory available to calculate such buckling behaviour, so the results could not be scaled up with confidence. Their solution to this problem was to rely on their experience and engineering judgement which, in this case, proved reliable.

A major breakthrough in the 1860s made it possible to deal with phenomena (such as the buckling of iron plates) whose precise engineering behaviour could not be described in theoretical terms. This was first achieved in the field of hydraulic engineering, in which the dynamics of fluid flow is both complex and non-linear, and could not be calculated using precise equations in the way that the bending of a beam could. A number of physicists developed a novel approach that allowed the behaviour of systems at different scales to be calculated without the need to know the precise physical laws governing the system. It was only necessary to know the relative relationship between a number of relevant parameters, and this could be achieved using dimensional analysis. The outcome of this process was, for a particular physical phenomenon, a certain dimensionless number (Addis 2021: 370-375). Perhaps the best known of these dimensionless numbers are the eponymous numbers devised by William Froude (1810-1879) and Osborne Reynolds (1842-1912) and, in the field of aerodynamics, Ernst Mach (1838-1916). It is largely due of the work of Froude and Reynolds that undertaking tests on reduced-scale measurement models became a reliable tool available to designers in architectural and civil engineering. The technique was first applied in structural engineering, for the buckling of thin, reinforced-concrete shells in the 1920s.

The heyday of structural modelling was from the mid-1950s to the mid-1970s. During this period the technique of model testing was developed to become a highly accurate and reliable design tool for those projects that were beyond previous experience and which required innovative solutions. Using dimensionless numbers it became relatively straight forward to take account of different scaling factors for each of the many different variables that had to be considered when building and testing models and interpreting the results at full scale. For a reinforced-concrete structure, for example, these could include linear dimensions, density, the applied load(s), Young's modulus, Poisson's ratio, the second moment of area of sections, the strength and perhaps even the coefficient of thermal expansion, brittleness, and creep behaviour. Sometimes the model materials were made to be as near to the fullscale material as possible, for example using micro-concrete; on other occasions, an entirely different material, such as Perspex, might be used because, being less stiff, deflections in the model would be larger and easier to measure.

\section{Some Case Studies}

\section{Leipzig Wholesale Market Hall, 1927-1930}

The wholesale market in Leipzig is an octagonal, reinforced-concrete dome with a span of $65.8 \mathrm{~m}$ between springings and, at the time, had the largest span of any similar building (Brunelleschi's dome has a span of about $44 \mathrm{~m}$ ) (Figs. 8, 9). It was built by the firm Dykerhof \& Widman AG (DYWIDAG) and the engineering design was led by Franz Dischinger (1887-1953). Although about a metre larger than the 


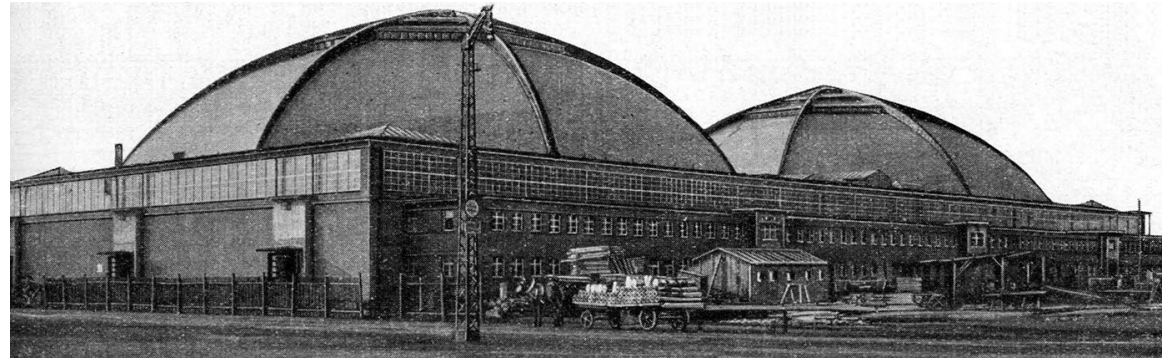

Fig. 8 The wholesale market hall, Leipzig, completed 1930. (Image: Dischinger 1930)

Fig. 9 Interior of the wholesale market, Leipzig, 1930. (Image: Public domain. https://commo ns.wikimedia.org/wiki/File: AHW_Betrieb_in_der_Gross markthalle_Leipzig_1930.jpg)

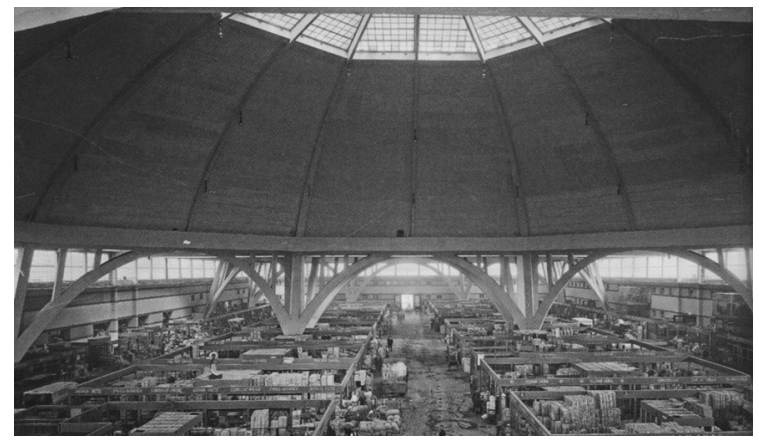

previous record holder, the Jahrhunderthalle in Breslau built in 1913, the dome at Leipzig was one third of its weight. In addition to its size and weight, the dome was innovative in being the first major dome made with a reinforced-concrete shell.

Each dome was made up of the segments of four intersecting barrel shells. At the ridge junctions between these sections, ribs were inserted to add stiffness to the shells and to provide a stiff load path down to the eight columns. The unsupported shell between the edge ribs was $27.2 \mathrm{~m}$ wide at the base and $11.5 \mathrm{~m}$ wide at the top; it was $9 \mathrm{~cm}$ thick and its length along the curved surface was about $27 \mathrm{~m}$. The shell had only slight curvature, which caused concerns about its buckling safety. Dischinger, the leading authority on reinforced-concrete shells, used von Mises equations for the buckling of cylindrical shells to estimate that the shell would have a safety factor against collapse of about six. However, Dischinger was aware that the geometry of the Leipzig shell was very different from the idealised cylinder and, for this reason, he undertook a series of tests on a 1:60 scale model of the dome (Figs. 10, 11). The model shell was made of steel sheet $1.5 \mathrm{~mm}$ thick with a span of $1.3 \mathrm{~m}$; it was surrounded by a second, slightly larger dome and both domes were mounted upside down with their edges embedded in concrete supports. The void between the domes was filled with water and the inner dome was loaded in compression by pressurising the water. This loading was radial rather than vertical, but was considered to be sensibly cautious in applying a horizontal component to the shell that could arise from wind loads or asymmetric snow loading. 
Fig. 10 1:60 Scale model for the dome of the Leipzig wholesale market hall, 1927. (Image: Dischinger 1930)

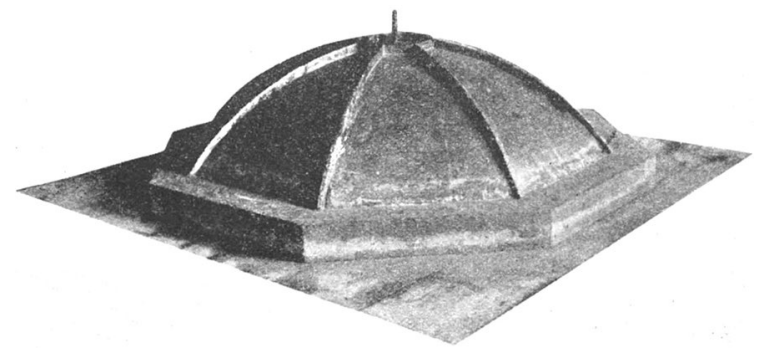

Schnitt A-B

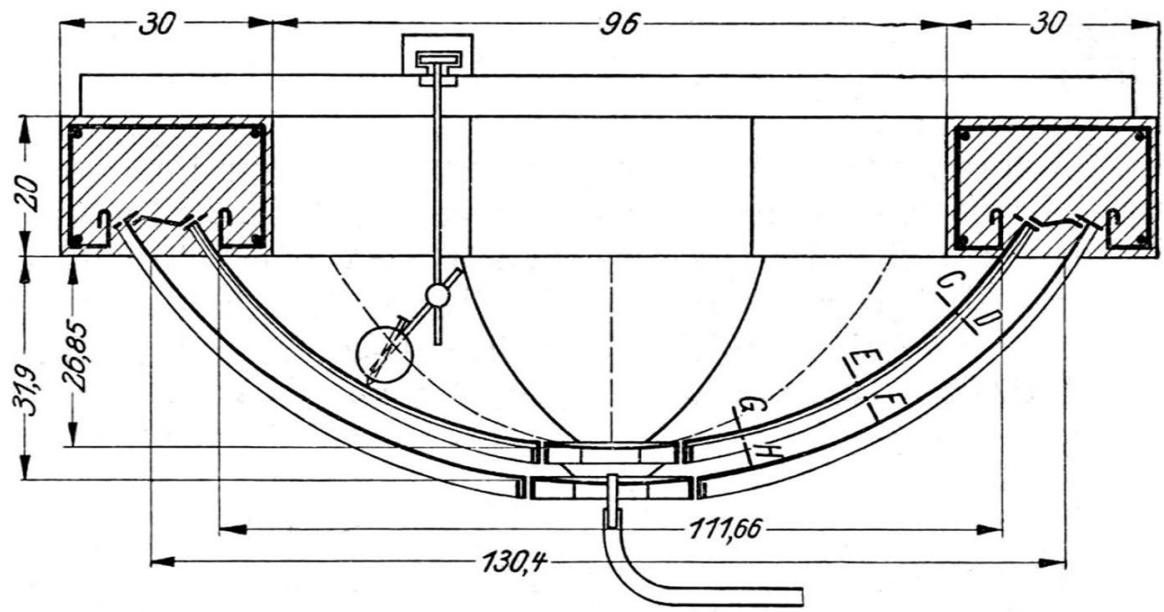

Schnitt C-D
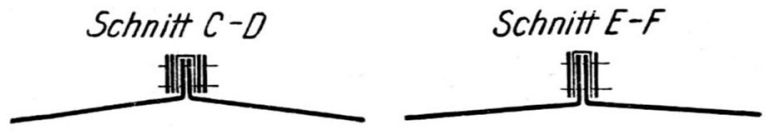

SChnitt G-H

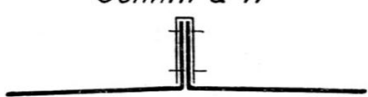

Fig. 11 Cross-section of the 1:60 scale model and test rig for the Leipzig dome. The model was made with steel sheet $1.5 \mathrm{~mm}$ thick and loaded in compression by hydrostatic pressure. (Image: Dischinger 1930)

The test confirmed the expected safety against buckling failure. However, even before failure, buckling waves had already formed in the shell and were measured using dial gauges. This unexpected effect would be problematic for the real dome made from reinforced concrete because of the inferior relationship between permissible stress and Young's modulus. It was therefore decided to explore the beneficial effect of inserting an additional stiffening rib in the middle of each shell segment. A further series of tests demonstrated the success of this measure and the dome was constructed in line with this result (Figs. 9, 12). 


\section{Poultry Market, Smithfield, London, 1961-1963}

The shell roof for the Smithfield Poultry Market in London, designed by Ove Arup \& Partners, was planned to be an elliptical-paraboloid shell, $68.6 \times 38.7 \mathrm{~m}$ in plan, with a rise of only $9.1 \mathrm{~m}$ (Fig. 13). The reinforced-concrete shell was to be $75 \mathrm{~mm}$ thick, except where it thickened towards the edges, and would be pierced by twenty-four skylights. It was constrained by a prestressed edge beam, which would tie the corners and would itself rest on thirty-two perimeter columns. The rise of this shell was extremely low and the roof was described as the 'boldest' shell ever constructed, where boldness is defined as the ratio span/(rise $\times$ thickness). This was a major innovation in shell construction. The best method of structural analysis for thin shells was 'membrane theory' but, as the designers said, 'the shortcomings of the membrane theory for the analysis of shell structures are well known. However, the theory is useful to obtain an approximate idea of the maximum direct stresses occurring in the shell' (Ahm and Perry 1965: 85). For a shell that was beyond previous experience, it was essential to investigate further the vulnerability to buckling of a surface of such small curvature, especially given the inadequacy of the available theoretical tools.

For this reason, the designers, Ove Arup \& Partners, commissioned the Cement and Concrete Association (C\&CA) to undertake a model study to determine whether buckling would be a critical factor in the design (Jones and Base 1965). A 1:12 scale model was constructed in micro-concrete reinforced with $1.2 \mathrm{~mm}$ diameter wire. 3600 spacers were needed to stabilise the reinforcement while the micro-concrete

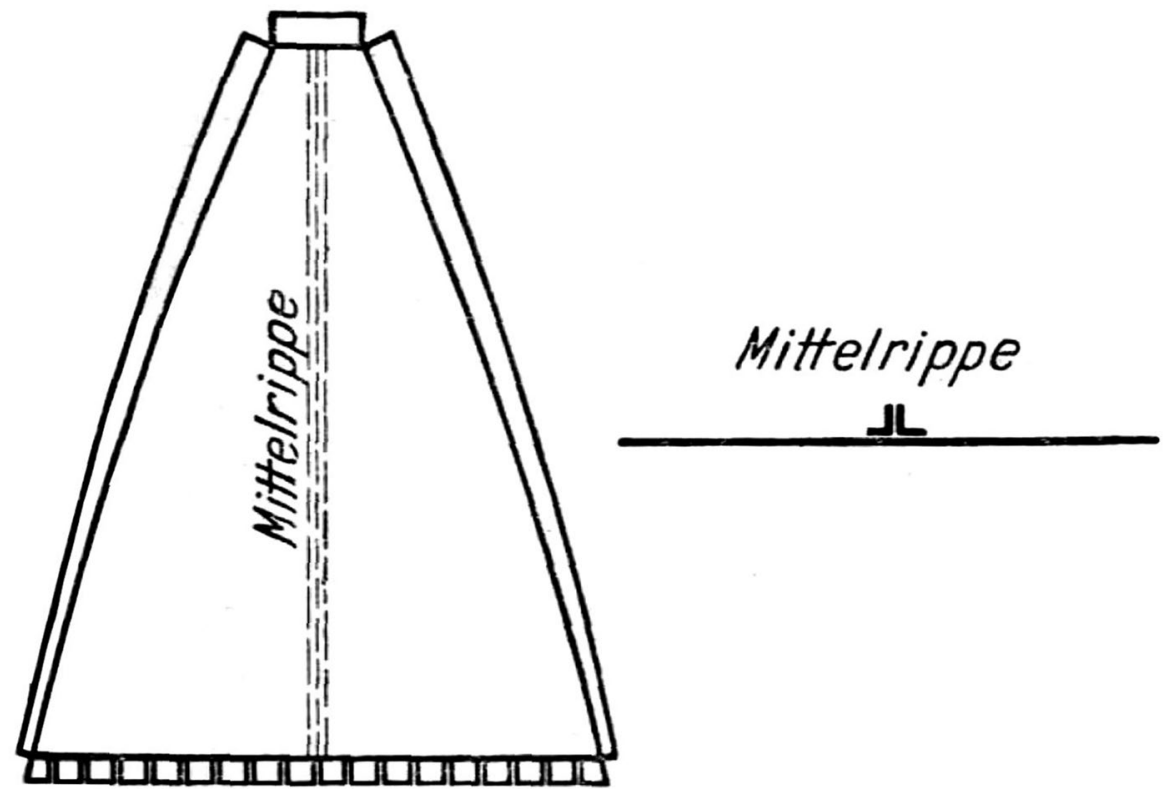

Fig. 12 The model was rebuilt with the insertion of an additional stiffening rib (Mittelrippe) in each shell segment and retested to verify the beneficial effect. (Image: Dischinger 1930) 


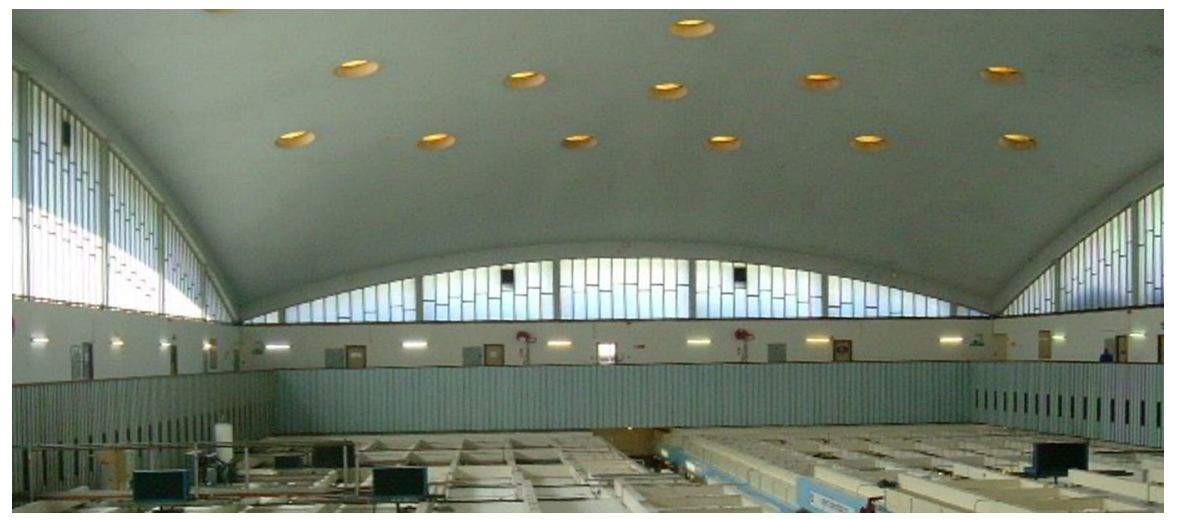

Fig. 13 Reinforced-concrete shell roof, Smithfield Poultry Market, London, 1963. (Image: Bill Addis)

was poured. Unlike the final design, prestress was applied to the shell externally. The dimensions of the model itself were impressive: $5.72 \times 3.23 \mathrm{~m}$ and just $6 \mathrm{~mm}$ thick (Fig. 14).

As with all model studies, it was essential to identify clearly the purposes of the tests. These were condensed into a number of key goals:

- Measure the elastic behaviour to validate the physical model;

- Compare measured behaviour of the model with the results of elastic analysis;

- Determine the loads on the perimeter columns;

- Determine deformation of the shell around the lighting holes;

- Verify that post-tensioning of the edge beams would lift the shell off its formwork;

- Establish the failure mode and failure load.

Fifty-five electrical-resistance, foil strain gauge rosettes $(12 \times 12 \mathrm{~mm})$ were attached to one quarter of the shell-a total of 330 active gauges. Deflections of the shell were measured to an accuracy of $1 / 1000$ of an inch $(0.025 \mathrm{~mm})$ using clock (dial) gauges attached by long wires to the shell in forty-four positions. (Fig. 15). Mechanical strain gauges were used to measure movement of the edges of the shell and the ring beam.

The load was applied pneumatically using eight air cushions in five different arrangements:

- Uniformly over all four quarters of the shell;

- On one half of the shell (divided by the short axis), measuring the behaviour of a loaded quarter;

- As above, measuring the behaviour of an unloaded quarter;

- On one half of the shell (divided by the long axis), measuring the behaviour of a loaded quarter;

- As above, measuring the behaviour of an unloaded quarter. 


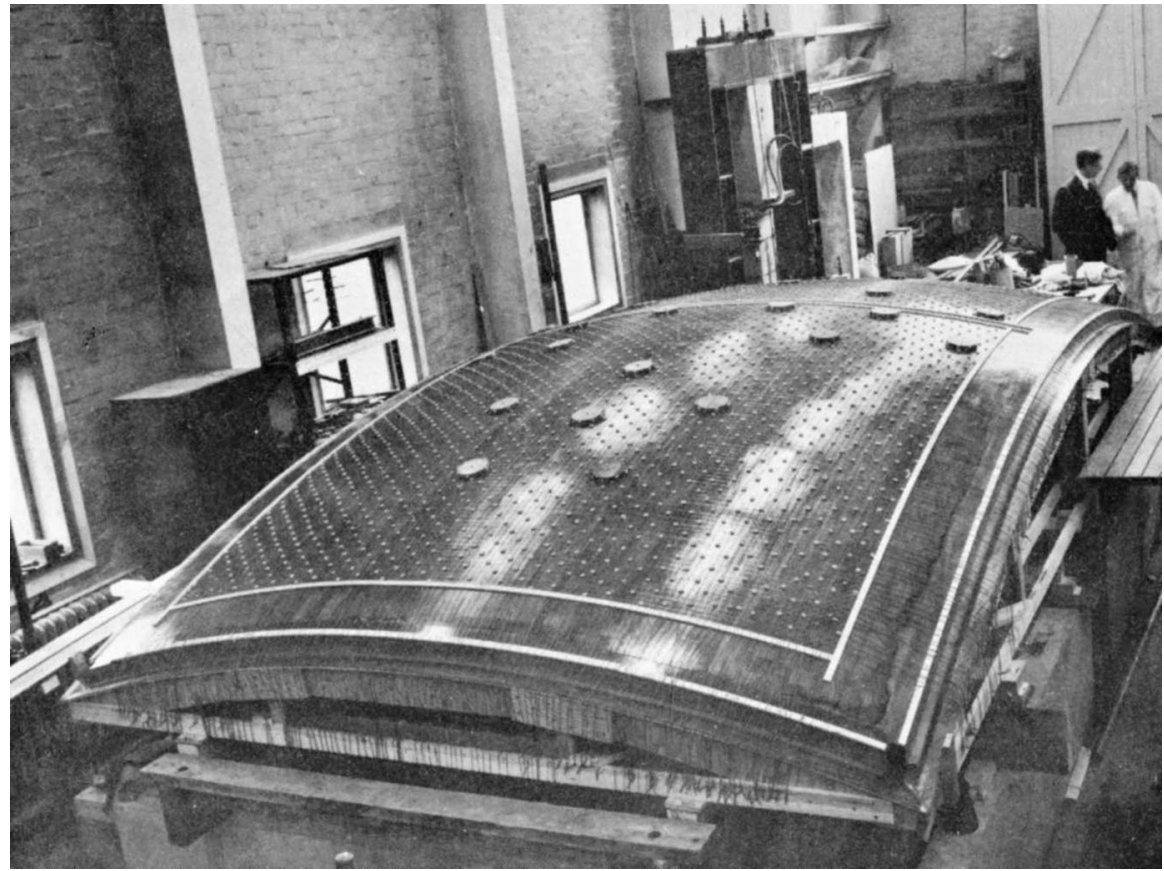

Fig. 14 1:12 Scale model for Smithfield Poultry Market, 5.72×3.23 m. Formwork and reinforcement are in place, awaiting the $6 \mathrm{~mm}$ layer of micro-concrete. (Image: C\&CA Archive)
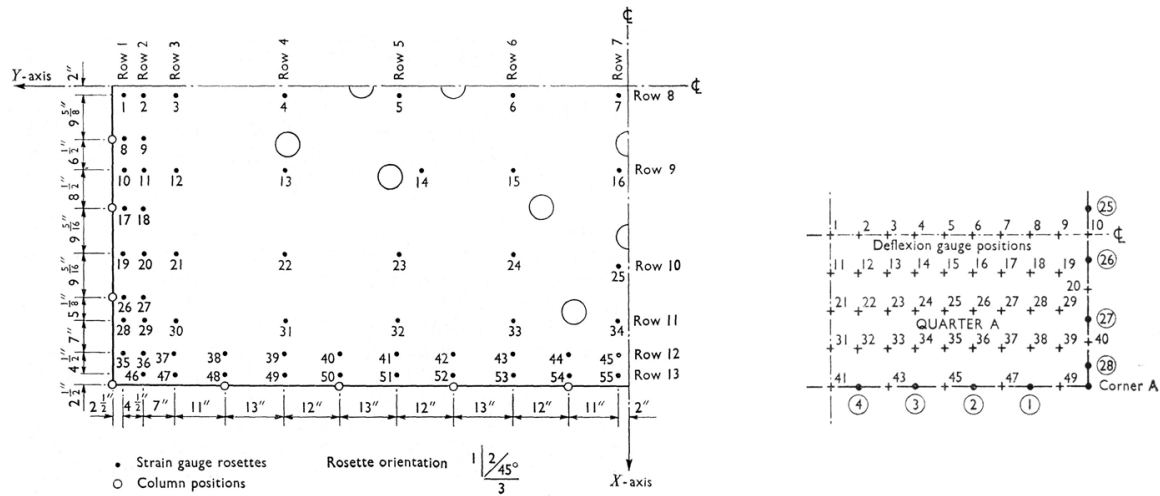

Fig. 15 Measuring points on the model. Left Positions of the 55 strain-gauge rosettes (on one quarter of the shell only). Right Positions of the 44 clock gauges for measuring vertical deflections of one quarter of the shell. (Image: C\&CA Archive)

The strain-gauge readings were recorded photographically but only 100 could be recorded for each load test. Given the number of loading patterns, the different sizes of loading and the limitations of recording the data, over 200 load tests had to 
be made, generating some 80,000 strain measurements during the 4-month testing programme.

The model was finally loaded to failure to determine the distribution of load (Fig. 16). The prestress in the edge beams was annulled when the load was only a little above the design load and so failure of the shell would be caused by the spread of cracks into the membrane. As the designer was more concerned with buckling load, the corners were heavily restrained to prevent failure initiating from the edge beams. Buckling failure was eventually achieved at a total load of $9.1 \mathrm{kN} / \mathrm{m}^{2}$, though this would have been much lower without the restraint. That accomplished, two undamaged sections of shell were retrieved and loaded to determine the modulus of elasticity.

The conclusions drawn from the series of tests yielded answers to the various questions posed. As expected, failure was by buckling (not shear); failure load was about four times the design load; direct stresses in the shell were low. Bending stresses were generally of a similar magnitude to direct stresses, but higher in the region of the edge thickening and there were no significant stress concentrations around the light holes. Prestressing had to be raised $40 \%$ to prevent cracking of the shell and it was verified that post-tensioning of the edge beams would raise the real shell $9 \mathrm{~mm}$ off the formwork to permit decentring.

The model tests resolved the designers' uncertainty about a number of issues and established the degree to which they could rely on the 'inadequate' membrane

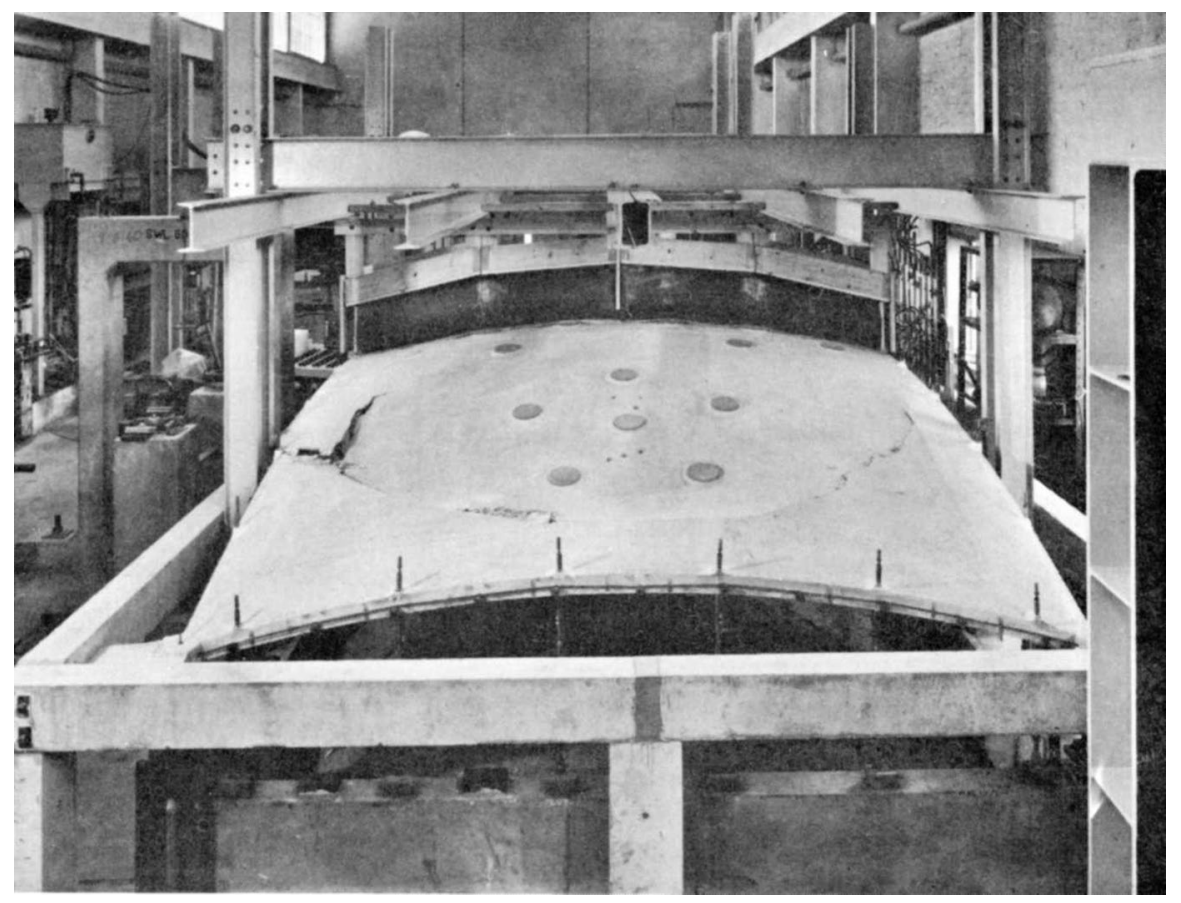

Fig. 16 The model just after failure. Four air bags are still in position on the undamaged half of the shell. The restraining ring beam is also visible. (Image: C\&CA Archive) 
theory. A number of modifications to the original design were implemented and, overall, the designers' level of confidence in their innovative design was raised to a sufficient level to begin construction.

\section{Staatsoper Unter den Linden, Berlin, (Renovation) 2010-2018}

The Staatsoper Unter den Linden (the Berlin State Opera House) was built in 1742 as the first detached court opera building in Europe. The building was severely damaged several times in its history and also restored or renovated several times. During the period from 2010 to 2017 the building was fully renovated and all technical equipment renewed. The acoustical aspects of the renovation of the 1350seat opera hall were vital to this restoration.

The key goals of the renovation were to achieve substantial improvements to the room acoustic of the hall by increasing its volume from 6500 to $9500 \mathrm{~m}^{3}$, to be achieved by raising the existing decorated ceiling by five metres into the attic space (Fig. 17). This major modification had to be achieved while at the same time preserving the architectural design and monumental status of the hall. Since the acoustic of the hall depends precisely on the geometry and the architecture, these goals represented an apparent contradiction in requirements. A bespoke and innovative solution was needed to reconcile these conflicting demands (Vercammen and Lautenbach 2018).

The first step was to precisely measure the acoustic characteristics of the existing hall, and to build a calculation model, using ray tracing, based on a simplified geometry of the interior space and acoustic properties for all the interior surfaces of the hall, including the seats both when occupied and unoccupied. The various parameters and details of the calculation model were adjusted to calibrate the model and achieve a good correspondence with the measured acoustic behaviour of the original hall. The calculation model was then rebuilt to represent the modified hall with the ceiling raised by $5 \mathrm{~m}$. This demonstrated that the new hall would achieve the longer reverberation time that was needed. However, the ray-tracing model does
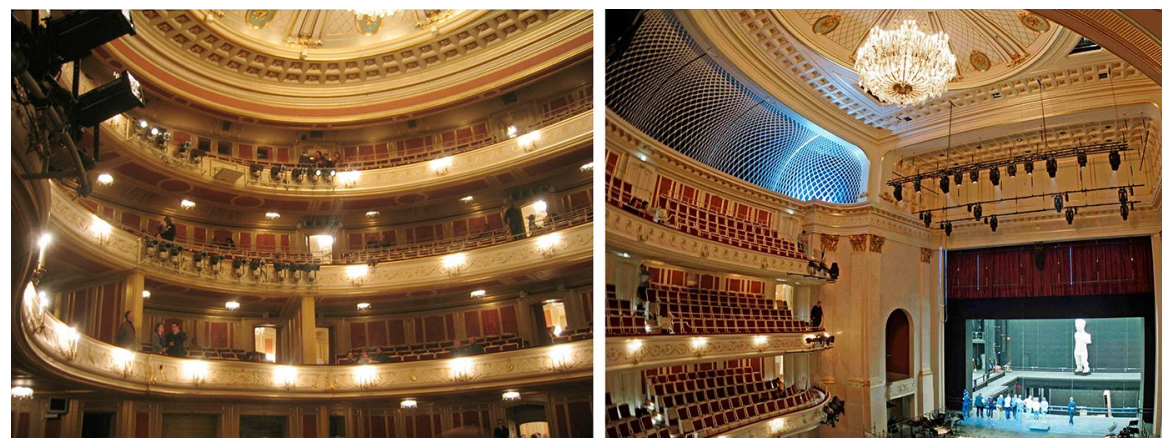

Fig. 17 Staatsoper, unter den Linden, Berlin. Left before renovation. (Image: Andreas Praefcke, https://commons.wikimedia.org/wiki/File:Berlin_Staatsoper_Zuschauerraum.jpg, Creative Commons Attribution 3.0 Unported license). Right After renovation, with a new gallery level. (Image: Peutz Associates) 
not take into account the wave nature of sound. To study this, it was necessary to build a physical model of the hall, at a scale of 1:10.

As with the calculation model, the physical model was built, first of all, to represent the original hall and the interior features and surfaces of the model were adjusted to achieve a good correspondence between the acoustics of the reducedscale model and the existing hall. This had to take into account the effects of scaling, for example, the frequency of the sound used in the model was ten times higher than full size, while the sound absorption of internal surfaces is not affected by scale. Furthermore, the degree to which humid air absorbs and attenuates sound increases significantly with frequency. It was therefore necessary to experiment with different types of interior surface and to apply correction factors to compensate for sound absorption by humid air. In this way, the model was calibrated and a good correspondence was achieved between the acoustic measurements from the model and the original hall.

The interior of the model is shown in Figs. 18 and 19. Members of the audience and a few musicians on stage were represented by pyramids of foam rubber which replicate the sound absorption of a person. The two black posts mounted on light circular bases, stage left, are the sound sources; the sound is emitted from a tiny opening at the top of the black cone. The three pairs of metallic rods on stage (and also in the audience areas) are the microphones. The small condenser microphones are mounted at the top and the preamplifiers fitted in the thicker part at the bottom. The sources and microphones are at standard heights - corresponding to $1.2 \mathrm{~m}$ for sources and $1.5 \mathrm{~m}$ for receivers at a scale of 1:10. A model listener, incorporating

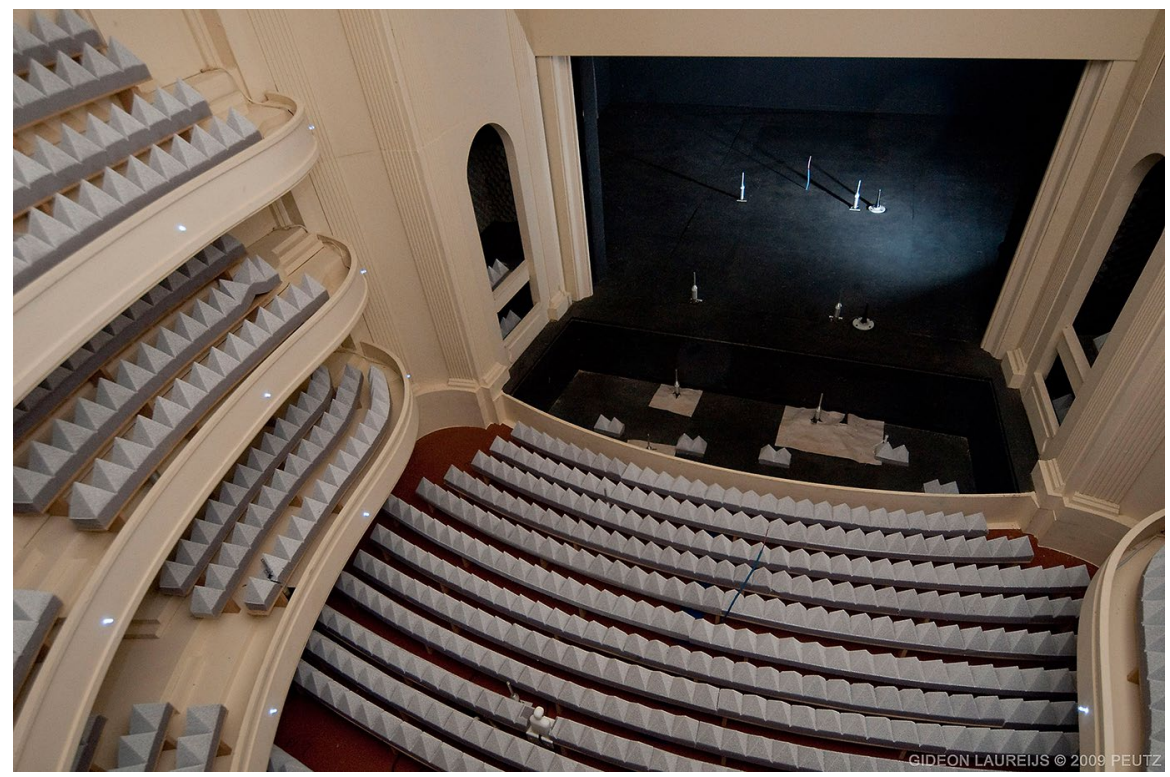

Fig. 18 1:10 Scale acoustic model of the Staatsoper in Berlin. (Image: Peutz Associates) 

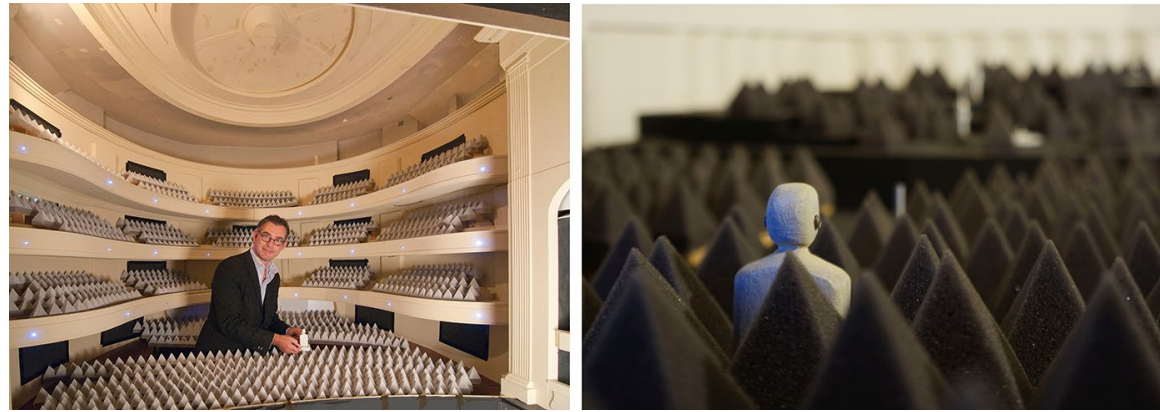

Fig. 19 Left 1:10 scale acoustic model of the Staatsoper in Berlin. The acoustician is holding a model listener whose ears are microphones for recording the sound at different places in the auditorium. Right A model listener. (Images: Peutz Associates)

small microphones, can be placed in any seat in the auditorium to enable the received sound to be recorded.

The model was then rebuilt to represent the new hall with the raised ceiling and increased volume. Many alternatives were studied using this model, for example to eliminate focused reflections that were discovered with the first version of the wall of the new gallery. In the final design, the visible wall was replaced with an acoustically transparent mesh with reflecting walls behind, hidden from view (Fig. 17, right). Other design options that were studied and optimised using the model included raising of the ceiling of the fore-stage, changing the orientation of the windows of the control room, lowering the orchestra pit, adding acoustic diffusers into the pit, and reflectors above the orchestra and the fore-stage boxes. For all these options there was constant interchange of results obtained from the physical model and the ray-tracing calculation model in order to achieve an optimal design.

By a process of successive innovations related to the many different acoustic characteristics of the auditorium, the final design managed to achieve the desired improvement in acoustics while respecting the architectural features of the original hall. The acoustic quality of the new auditorium has been praised by the owner of the opera house, musicians and audiences.

\section{Conclusions}

Physical models have been used in the design process for innovative engineering projects for centuries. We have a good records of their use from the 1840s, and since then they have been used together with the currently available engineering science (theory) to gain a sufficiently good understanding of an innovative project to raise an engineer's confidence in the design to a level sufficient to allow construction to commence.

The paper has demonstrated that engineers use physical models only when there is a need to do so which, by definition, is when a project cannot be designed using 
contemporary engineering theory and familiar design methods-in other words, when a project is innovative.

The use of measurement models has declined since the mid-1970s as the reliability and power of computers has grown, and engineering science has become more and more sophisticated and able to represent more and more complex engineering phenomena. However, models are still widely used where innovation is demanded in relation to those engineering phenomena which still cannot be reliably captured by mathematical models that can be processed by computers. In the field of architectural and civil engineering these include the impact of wind on engineering structures, the movement of water in rivers, estuaries and tidal zones, the behaviour of both old and new structures in earthquakes, the acoustics of buildings, and for the design particularly unusual structures.

Acknowledgements The images in Figs. 3, 4, 5, 6, 14, 15, 16, 18 and 19 previously appeared in Bill Addis (Ed.) Physical Models: Their historical and current use in civil and building engineering design. 2021. Copyright Wilhelm Ernst \& Sohn Verlag für Architektur und technische Wissenschaften GmbH \& Co. KG. Reproduced with permission.

Funding Open Access funding enabled and organized by Projekt DEAL.

Open Access This article is licensed under a Creative Commons Attribution 4.0 International License, which permits use, sharing, adaptation, distribution and reproduction in any medium or format, as long as you give appropriate credit to the original author(s) and the source, provide a link to the Creative Commons licence, and indicate if changes were made. The images or other third party material in this article are included in the article's Creative Commons licence, unless indicated otherwise in a credit line to the material. If material is not included in the article's Creative Commons licence and your intended use is not permitted by statutory regulation or exceeds the permitted use, you will need to obtain permission directly from the copyright holder. To view a copy of this licence, visit http://creativeco mmons.org/licenses/by/4.0/.

\section{References}

Addis, W. 1990. Structural Engineering - the Nature of Theory and Design. Chichester: Ellis Horwood.

Addis, W. (Ed.). 1999. Structural and Civil Engineering Design. Vol.12 of the series 'Studies in the History of Civil Engineering'. Aldershot: Ashgate (Variorum).

Addis, Bill. 2003. The nature of progress in construction engineering history. In: Proceedings of the First International Congress on Construction History, Madrid, edited by S. Huerta, et al., 123-129. Madrid: Instituto Juan de Herrera.

Addis, Bill. 2005. A history of using models to inform the design of structures. In: Essays in the History of the Theory of Structures: In honour of Jacques Heyman, edited by Santiago Huerta, 9-44. Madrid: Instituto Juan de Herrera.

Addis, Bill. 2007. Building: 3000 years of Design, Engineering and Construction. London \& New York: Phaidon.

Addis, Bill. 2013. 'Toys that save millions': a history of using physical models in structural design. The Structural Engineer. 91 (4 April): 11-27.

Addis, Bill, 2014. Physical modelling and form finding. In: Shell Structures for Architecture: Form Finding and Optimization, edited by, S. Adriaenssens, P. Block, D. Veenendaal and C. Williams, 32-43. Abingdon: Routledge.

Addis Bill, (Ed.). 2021. Physical Models: Their historical and current use in civil and building engineering design. Wilhelm Ernst \& Sohn.

Ahm, Povl and Edwin John Perry. 1965. Design of the dome shell roof for Smithfield Poultry Market. Proc. ICE 30 (1): 79-107. 
Bach, Klaus, Frieder Klenk and Frei Otto. 1987. Seifenblasen: Forming bubbles. Mitteilungen des Instituts für leichte Flächentragwerke (IL 18). Stuttgart: Krämer.

Bühler, Dirk. 2021. Models in civil engineering from ancient times to the Industrial Revolution. In: Physical Models: Their historical and current use in civil and building engineering design, ed. Bill Addis, 3-30. Wilhelm Ernst \& Sohn.

Chilton, John. 2000. Space Grid Structures. Oxford: Architectural Press.

Clark, Edwin. 1850. The Britannia and Conway Tubular Bridges, with General Inquires on Beams and on the Properties of Materials Used in Construction. London: Day.

Dischinger, Franz. 1930. Die Großmarkthalle Leipzig. Zeitschrift des Vereines deutscher Ingenieure 74(1): 7-10.

Euler, Leonhard. 1776. Regula facilis pro diiudicanda firmitate pontis aliusve corporis similis excognita firmitate moduli. Novi Commentarii academiae scientiarum Petropolitanae 20: 271-285, Plate II Figs 7-9. Eng. trans. in: Physical Models: Their historical and current use in civil and building engineering design, ed. Bill Addis, 1053-1060. Wilhelm Ernst \& Sohn.

Fairbairn, William. 1849. An Account of the Construction of the Britannia and Conway Tubular Bridges, with a Complete History of their Progress [...]. London: Weale.

Galilei, Galileo. 1638. Two new sciences (Eng. trans. Henry Crew and Alfonso de Salvio, 1914). New York: Dover Publications.

Graefe, R. 2021. The catenary and the line of thrust as a means for shaping arches and vaults. In: Physical Models: Their historical and current use in civil and building engineering design, ed. Bill Addis, 79-126. Wilhelm Ernst \& Sohn.

Happold, E. and W. I. Liddell. 1975. Timber Lattice Roof for the Mannheim Bundesgartenschau. The Structural Engineer 53 (3): 99-135.

Huerta, S. 2021. Block models of the masonry arch and vault. In: Physical Models: Their historical and current use in civil and building engineering design, ed. Bill Addis, 31-77. Wilhelm Ernst \& Sohn.

Jones, Leonard Leslie and Geoffrey Donald Base. 1965. Test on a one-twelfth scale model of the dome shell roof for Smithfield Poultry Market. Proc. ICE 30 (1): 109-130.

Kawaguchi, Mamoru. 1998. Neuartige Tragwerke und ihre Formen - Beispiele des Pantadome-Systems. In: Bautechnik 75 (11): 948-954

Kawaguchi, M. and M. Abe. 1992. Design and construction of Sant Jordi Sports Palace. Bulletin of the IASS 33(2), no.109: 69-88.

Vercammen, Martijn and Margriet Lautenbach. 2018. Staatsoper Unter den Linden Berlin. Proceedings of the Institute of Acoustics 40 (3): 64-72.

Publisher's Note Springer Nature remains neutral with regard to jurisdictional claims in published maps and institutional affiliations.

Bill Addis has devoted some 40 years to studying the history of architectural and civil engineering and materials, focusing on the historical development of engineering design. He is the author of over 100 publications on these subjects. He began his career as an engineer in the aero-engine industry with Rolls Royce and later taught at Reading University for more than 15 years. From 2000 to 2015 he worked as a Consulting Engineer at the engineering firm Buro Happold in London. For 5 years he was co-editor of Construction History, the journal of the Construction History Society; for 6 years he chaired the editorial board of Engineering History and Heritage, a journal of the Institution of Civil Engineers in London. He has been a member of the Scientific Advisory Boards for Spanish, French and English Construction History Congresses, as well as six international congresses in Cambridge, Cottbus, Paris, Chicago, Brussels and Lisbon. Since his retirement 6 years ago, he has been a visiting professor of construction history at universities in Rome, Innsbruck, Brussels, Zurich and Munich 